\title{
HOW GREEN WERE THE OCEANS IN THE PAST?
}

\section{Get the answer from an awesome "bug" buried in the mud}

Iván Hernández-Almeida and Mariem Saavedra-Pellitero

When we look beyond the clouds, at the starry night, there are eyes looking back at us. Sentinels in space, able to see colors in the blue abyss of the sea.
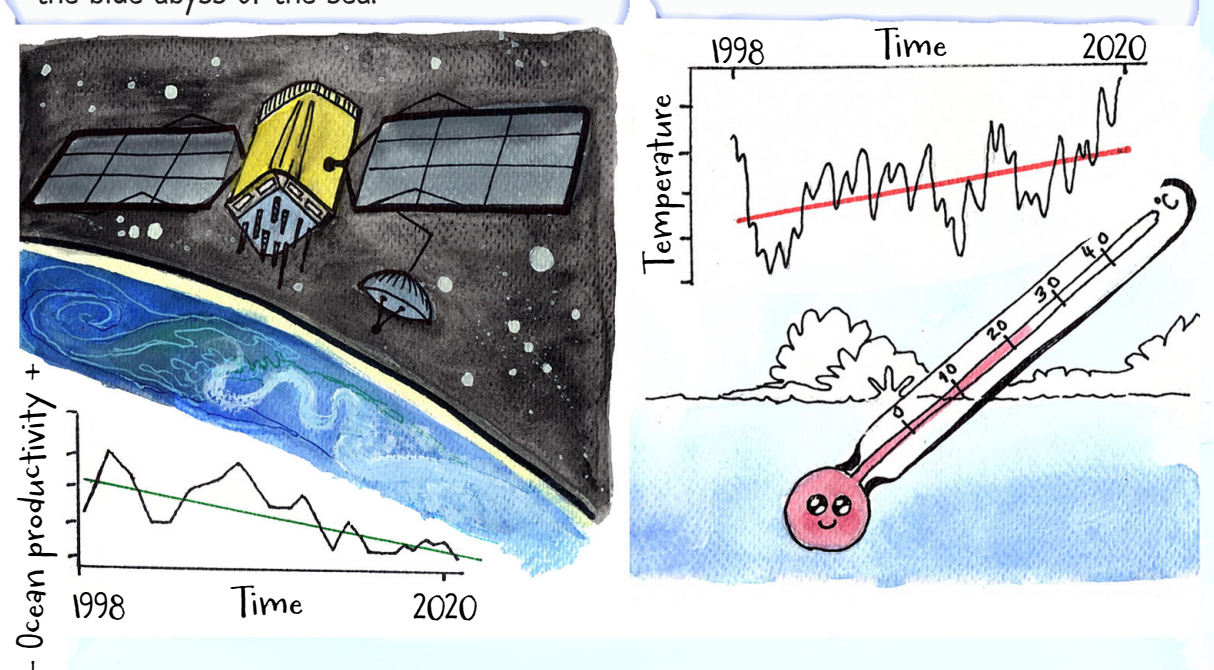

But their memory is short, going back not much further than the year you were born.

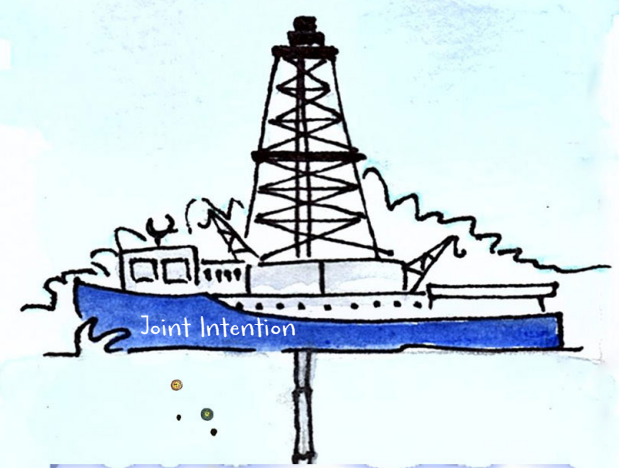

To have a peek beyond, further into the past, we must dig into the mud. Fine layers of sand and clay, alternating like a chocolate cake, are like pages of a book. Each slice, a grasp of time, traps the remains of "bugs" that lived,

bloomed and died.

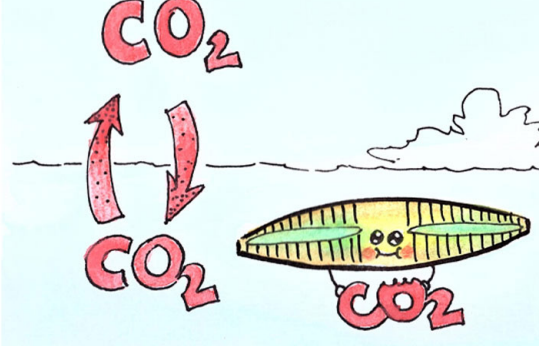

You may have heard that tiny algae creatures, invisible to the naked eye, are the trees of the ocean. You may have been told that these algae might hold the key to combat GLOBAL WARMING.

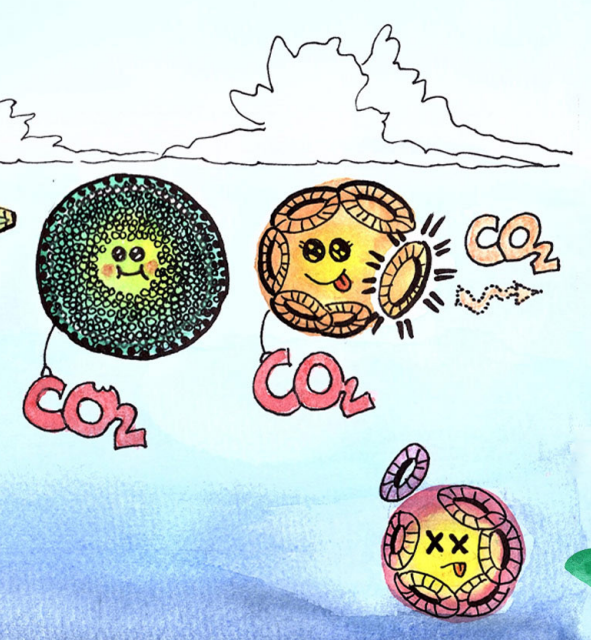

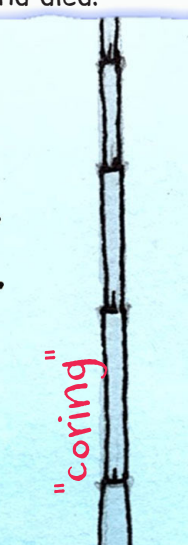

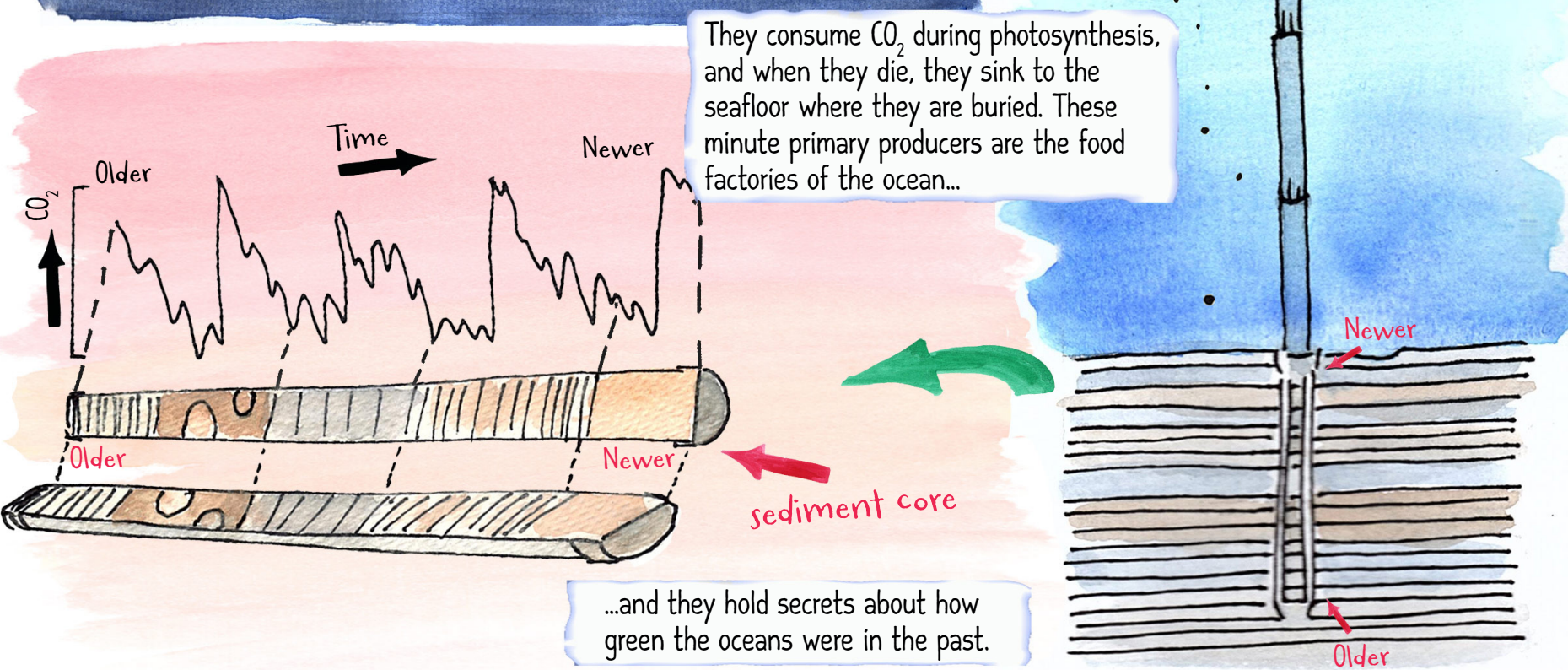



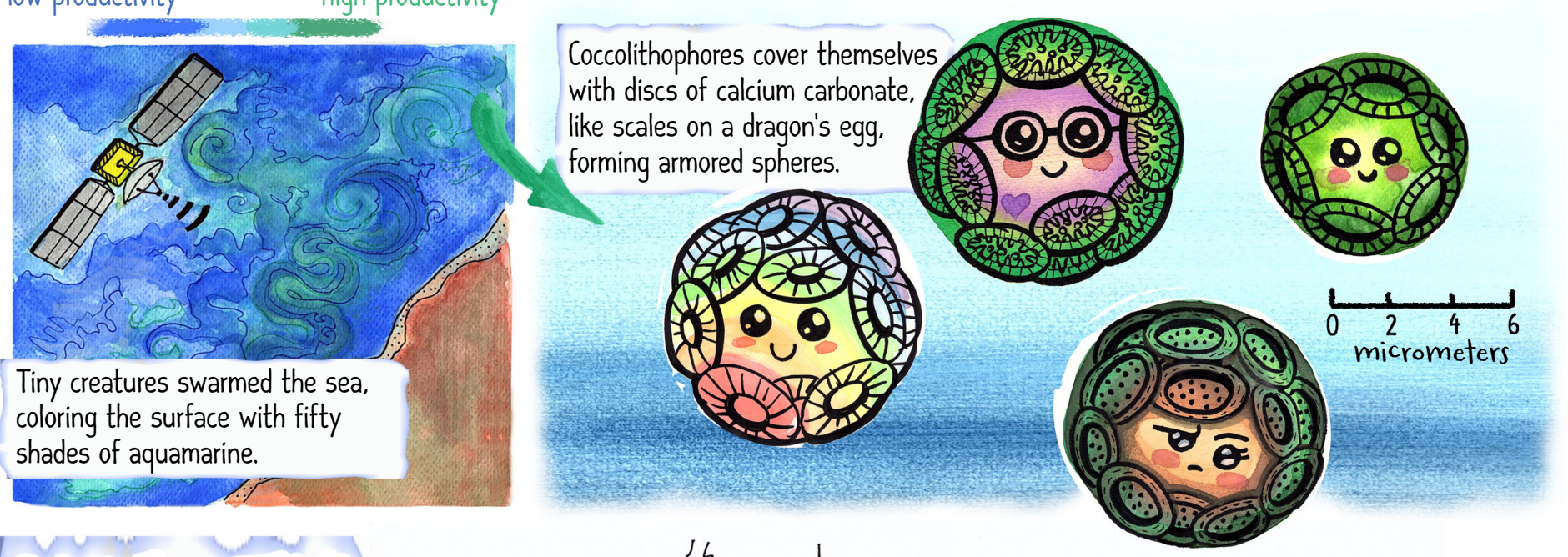

You may have been told that these algae thrive everywhere in the ocean. But this is not entirely true. There are vast areas of the ocean that are like deserts for life.

The tropical oceans are heated throughout most of the year. They turn into a warm soup that rarely mixes. Although sunlight is not a problem, nutrients are rare and lie deeper in the ocean.

One of these coccolithophore algae, called Florisphaera profunda, loves living deep, in this warm soup, and it is rarely found in cold waters.

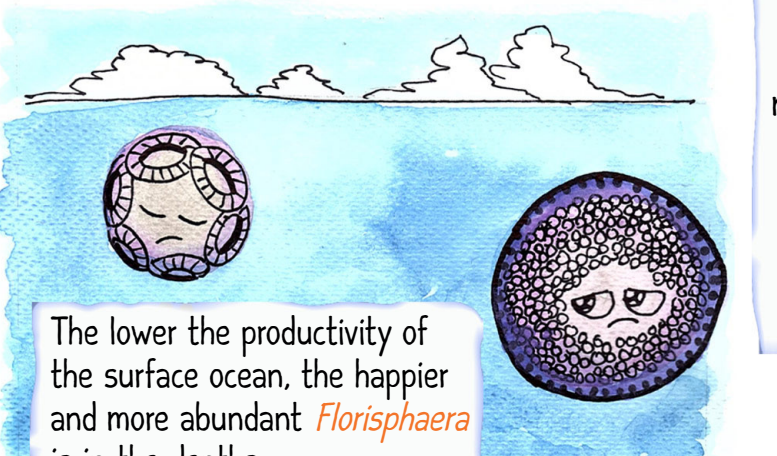

is in the depths.

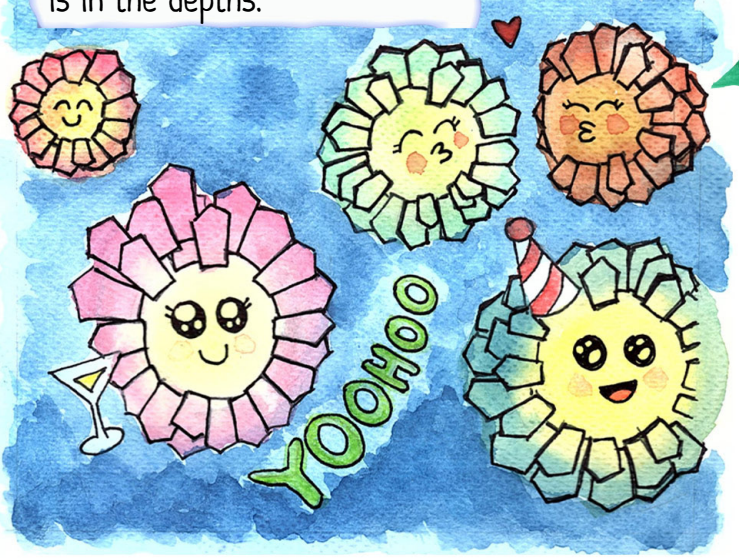

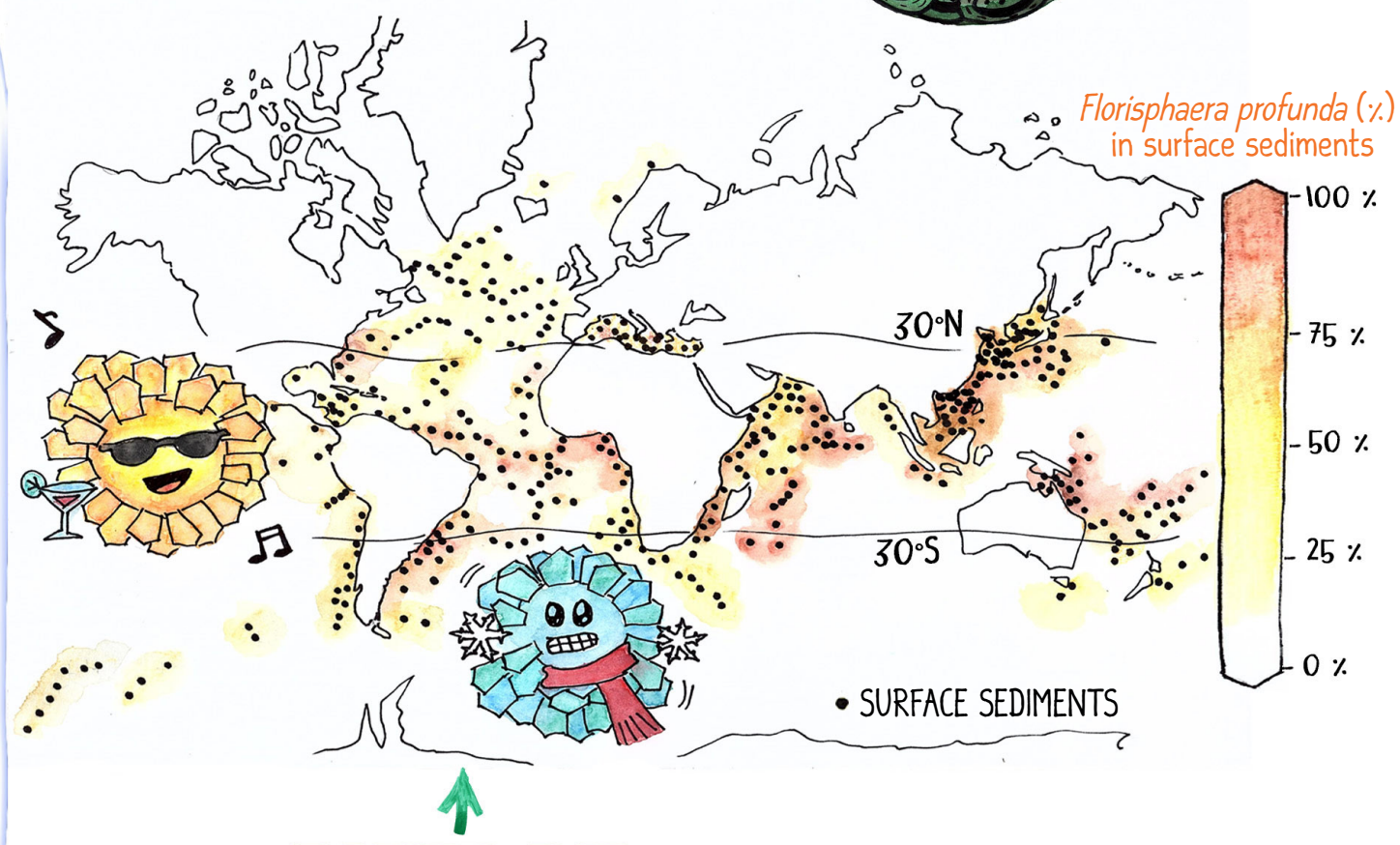

Using the abundance of Florisphaera in surface sediments (=same as modern ocean conditions) and comparing to satellite productivity measurements, we can reconstruct past ocean primary productivity!

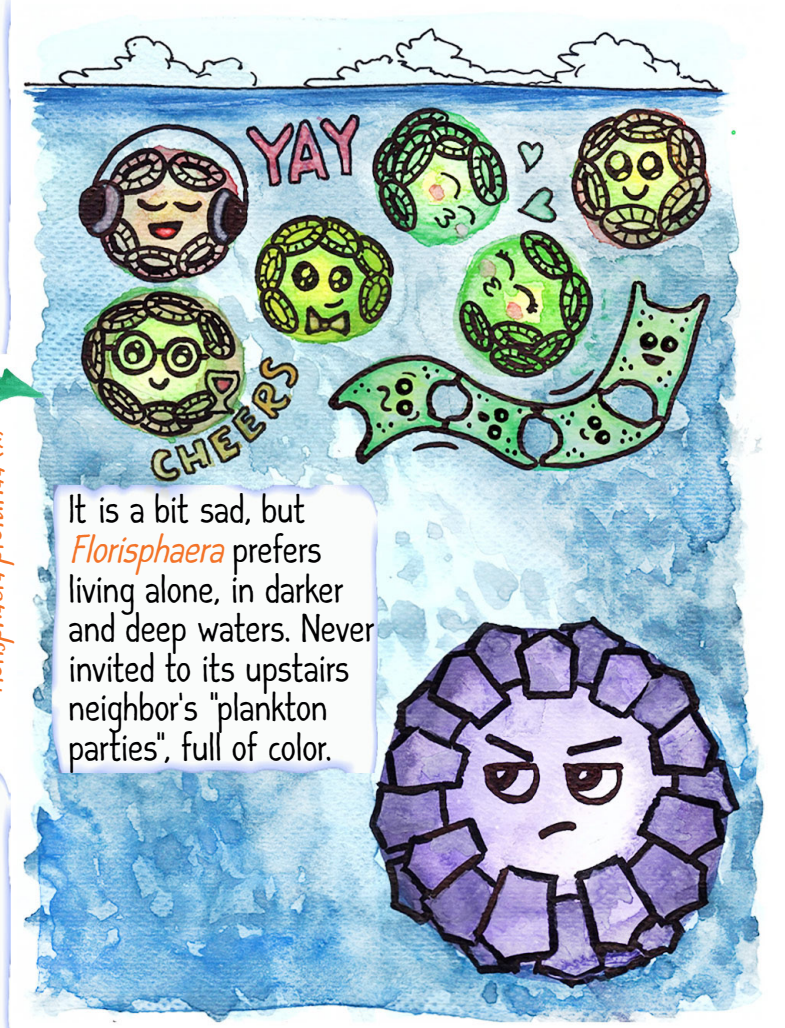


We studied Florisphaera in many sediment cores around the globe, and used that relationship.

We see that...

...thousands of years in the past, when ice-sheets were larger than today and global temperatures colder, winds also blew stronger, mixing surface ocean waters. Photosynthesis was higher, meaning more carbon was transferred into the deep ocean. Florisphaera got a bit upset. With all this higher productivity, it was a bit distressed!
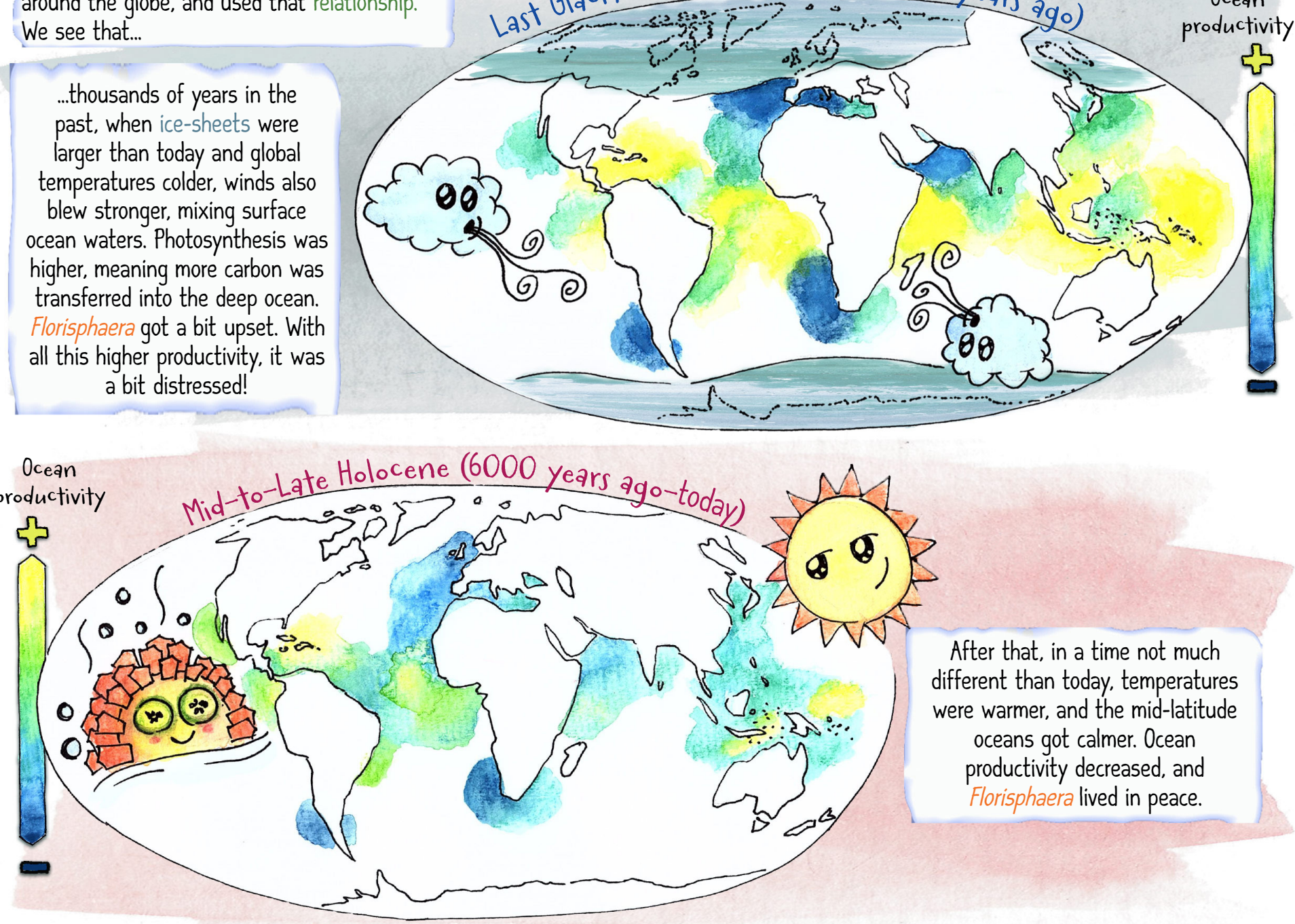

After that, in a time not much different than today, temperatures were warmer, and the mid-latitude oceans got calmer. Ocean productivity decreased, and Florisphaera lived in peace.

Our eyes from space tell us that the low-latitude deserts in the ocean are becoming larger. Rising temperatures of the planet warm up the ocean too. Marine plant life slows down and absorbs less carbon.

WHAT WILL HAPPEN IN THE FUTURE?

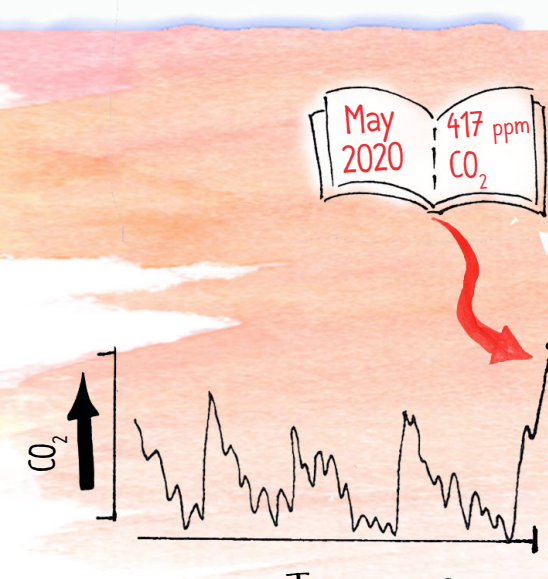

Time

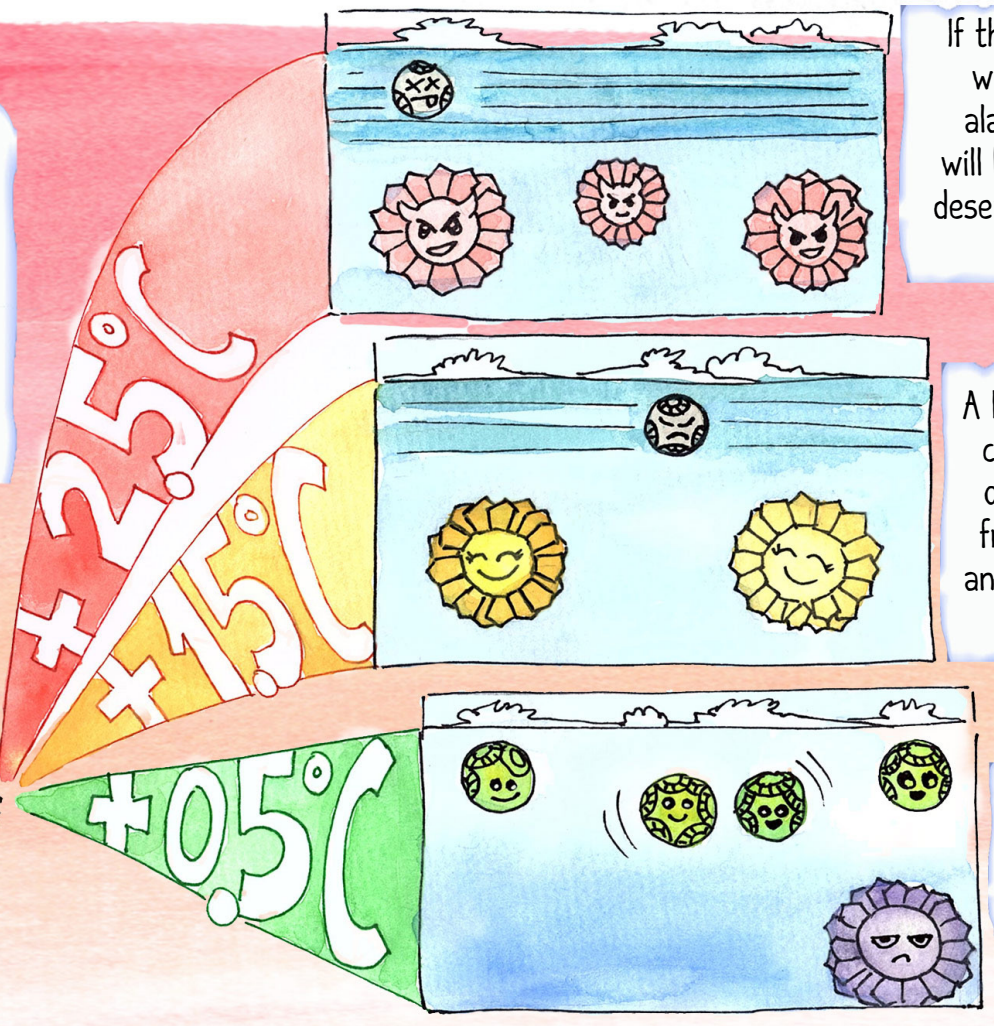

If the planet gets really warm, we should be alarmed! Florisphaera will be happier when the deserts in the oceans will get larger!

A little bit of warm can cause harm! Surface ocean color will turn from green to brown, and productivity will go down!

Only if we take a strong stand can we prevent such change! 